\title{
Atrial Fibrillation and Minimally Invasive Coronary Artery Bypass Grafting: Risk Factor Analysis
}

\author{
Xavier M. Mueller, M.D., Hendrik T. Tevaearai, M.D., Patrick Ruchat, M.D., Frank Stumpe, M.D., \\ Ludwig K. von Segesser, M.D. \\ Clinic for Cardiovascular Surgery, Centre Hospitalier Universitaire Vaudois, CH-1011 Lausanne, Switzerland
}

Published Online: March 1, 2002

\begin{abstract}
Atrial fibrillation (AF) is a frequent arrhythmia after conventional coronary artery bypass grafting. With the advent of minimally invasive technique for left internal mammary artery-left anterior descending coronary artery (LIMA-LAD) grafting, we analyzed the incidence and the risk factors of postoperative $A F$ in this patient population. This prospective study involves all patients undergoing isolated LIMALAD grafting with minimally invasive technique between January 1994 and June 2000. Twenty-four possible risk factors for postoperative AF were entered into univariate and multivariate logistic regression analyses. Postoperative AF occurred in 21 of the 90 patients (23.3\%) analyzed. Double- or triple-vessel disease was present in $12 / 90$ patients $(13.3 \%)$. On univariate analysis, right coronary artery disease $(p<0.01)$, age $(p=$ $0.01)$, and diabetes $(p=0.04)$ were found to be risk factors for AF. On multivariate analysis, right coronary artery disease was identified as the sole significant risk factor $(p=0.02)$. In this patient population, the incidence of AF after minimally invasive coronary artery bypass is in the range of that reported for conventional coronary artery bypass grafting. Right coronary artery disease was found to be an independent predictor, and this may be related to the fact that in this patient population the diseased right coronary artery was not revascularized at the time of the surgical procedure. For the same reason, this risk factor may find a broader application to noncardiac thoracic surgery.
\end{abstract}

Atrial fibrillation (AF) is a frequent arrhythmia after coronary artery bypass grafting, occurring in $20 \%$ to $40 \%$ of patients [1-5]. Although usually benign, it may lead to severe complications including hemodynamic instability and systemic embolization [6, 7] with prolongation of the hospital stay. Consequently, AF after coronary artery bypass grafting leads to increased use of resources [3].

Moreover, despite the progress in anesthetic and surgical techniques, the incidence of $\mathrm{AF}$ has not changed, and it may even increase with the aging patient population [3]. Numerous studies have attempted to identify the predictors of AF. Their number reflects the failure to prevent this arrhythmia in unselected patients. So far, only increased age has consistently been associated with $A F$ after coronary artery bypass grafting [1-5].

The recent introduction of minimally invasive technique through a small left anterior thoracotomy has gained popularity

Correspondence to: X.M. Mueller, M.D., e-mail: xavier.mueller@chuv. hospvd.ch mainly for isolated left internal mammary artery (LIMA)-left anterior descending coronary artery (LAD) grafting. This technique obviates the need for cardiopulmonary bypass and cardioplegia preservation. Two studies have directly compared the incidence of postoperative AF in this patient group with that of standard coronary artery bypass grafting patients $[8,9]$. Neither study could establish a significant difference, suggesting that other factors than extracorporeal circulation, global myocardial ischemia, and myocardial preservation technique are determinants for the occurrence of this arrhythmia.

Data on determinants of postoperative AF after LIMA-LAD grafting through a minimally invasive approach are lacking, and it was therefore the aim of the present study to analyze these risk factors.

\section{Patients and Methods}

\section{Study Patients}

The study population consisted of all patients undergoing isolated LIMA grafting onto the LAD at our institution from January 1997 to June 2000 . In cases of double or triple vessel disease, a percutaneous dilatation of the other(s) vessel(s), when feasible, was planned after the first postoperative week. Patients with a chronic AF were excluded from the study. No patient had significant valve disease requiring surgical intervention. Information regarding each patient's past medical history, operative procedure, and postoperative course were prospectively recorded. We adopted a conservative policy of hospital stay, which was dictated by the fact that, when discharged, most of our patients went back home directly.

\section{Surgical Technique}

The minimally invasive direct procedure consisted of grafting the LIMA to the LAD either directly or by interposing a segment of epigastric artery with the " $\mathrm{H}$ graft technique" as described by Cohn et al. [10] (Fig. 1). The chest was opened through the 4th or 5 th intercostal space. The patient was heparinized $(100 \mathrm{IU} / \mathrm{kg})$ 

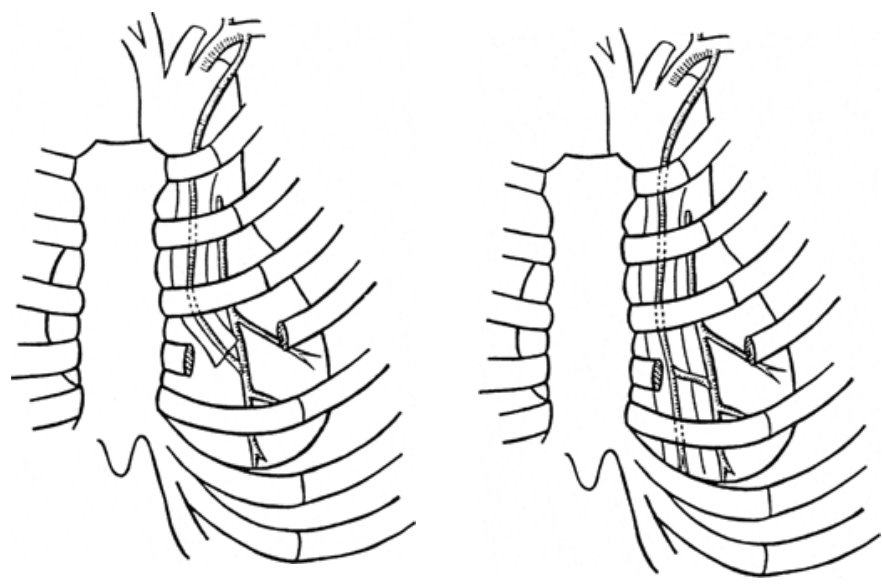

Fig. 1. Depiction of both minimally invasive techniques of left anterior descending artery (LAD) revascularization. Left. The left internal mammary artery (LIMA), which has been freed from the thoracic wall and transsected, is grafted directly to the left anterior descending coronary artery (LAD). Right. A segment of epigastric artery is interposed between the in situ LIMA and the LAD: the "H graft."

after the conduit harvesting. The pericardium was incised and traction sutures were applied to its edge. A snare of $4 / 0$ Prolene (Ethicon GmbH and Co. KG, Norderstedt, Germany) was applied proximally and distally to the site selected for the anastomosis. Short-acting calcium channel blockers were used to reduce heart rate when necessary. Anastomosis of the LIMA to the LAD was accomplished with the help of a stabilizer. At completion of the procedure a left pleural drain was left in place.

\section{Clinical Evaluation}

All patients had continuous cardiac rhythm monitoring for 72 hours. Transient atrial arrhythmias that could not be confirmed by an electrocardiogram were not included in the study. Only arrhythmias that required either medication or pacing were retained for analysis. After cessation of continuous monitoring, arrhythmias were identified by twice-daily pulse palpation or by clinical signs and symptoms and confirmed by a 12-lead electrocardiogram. In all patients a routine electrocardiogram was performed on the seventh postoperative day.

The relation of $A F$ to 24 perioperative variables was evaluated. Preoperative variables included age, gender, previous cardiac operation, presence of diabetes, hypertension, creatinine $\geq 120$ $\mu \mathrm{mol} / \mathrm{L}$, chronic obstructive pulmonary disease, coronary anatomy including significant right coronary artery and left circumflex coronary artery disease, and premature atrial contractions on the preoperative electrocardiogram; a history of supraventricular arrhythmia, smoking, and myocardial infarction; unstable angina and ejection fraction. Preoperative use of digitalis, calcium channel blocking agent, and $\beta$-blocking agent was also evaluated. Potential operative predictors of postoperative AF included the technique of grafting (direct vs. $\mathrm{H}$-graft technique) and the lowest systemic temperature achieved. The following postoperative factors were analyzed: reoperation for hemorrhage, myocardial infarction, the need for inotrope support, and ventilation of more than 24 hours.
Table 1. Preoperative variables.

\begin{tabular}{lccc}
\hline Variable & $\begin{array}{c}\text { SR group } \\
(n=69)\end{array}$ & $\begin{array}{c}\text { AF group } \\
(n=21)\end{array}$ & $p$ value \\
\hline Age (years) & $61.4 \pm 9.2$ & $67.7 \pm 5.9$ & 0.01 \\
Male & $84.1 \%$ & $85.7 \%$ & 0.7 \\
Previous cardiac operation & $1.4 \%$ & $4.8 \%$ & 0.42 \\
RCA disease & $4.3 \%$ & $28.6 \%$ & $<0.01$ \\
LCX disease & $8.7 \%$ & $14.3 \%$ & 0.57 \\
Diabetes & $8.7 \%$ & $28.6 \%$ & 0.04 \\
Hypertension & $56.5 \%$ & $52.4 \%$ & 0.47 \\
Creatinine $\geq 120 \mu$ mol/L & $5.8 \%$ & $14.3 \%$ & 0.27 \\
COPD & $5.8 \%$ & $9.5 \%$ & 0.65 \\
History of smoking & $60.9 \%$ & $47.6 \%$ & 0.11 \\
History of supraventricular & $2.9 \%$ & $9.5 \%$ & 0.25 \\
$\quad$ arrhythmias & & & \\
PAC & $1.4 \%$ & $9.5 \%$ & 0.1 \\
Post MI & $36.2 \%$ & $38.1 \%$ & 0.82 \\
Ejection fraction & $52 \pm 6.7 \%$ & $53.1 \pm 5.1 \%$ & 0.47 \\
Preoperative calcium & $37.7 \%$ & $28.6 \%$ & 0.55 \\
$\quad$ antagonist & & & \\
Preoperative $\beta$-blockers & $66.6 \%$ & $76.2 \%$ & 0.26 \\
Preoperative digitalis & $2.9 \%$ & $14.3 \%$ & 0.07 \\
Unstable angina & $13 \%$ & $9.5 \%$ & 0.66 \\
\hline
\end{tabular}

AF: atrial fibrillation; COPD: chronic obstructive lung disease; LCX: left circumflex artery; MI: myocardial infarction; PAC: premature atrial contraction; RCA: right coronary artery; SR: sinus rhythm.

\section{Statistics}

All data were entered into a spreadsheet (Microsoft Excel 4) and analyzed with Sigma Stat (SPSS Inc., Chicago, IL, USA). Univariate analysis of the influence of categoric variables on postoperative occurrence of AF was performed with a $\chi^{2}$ test. Continuous data were analyzed by logistic regression. Independent predictors of $\mathrm{AF}$ were determined by using a multivariate logistic regression analysis that included the variables identified as significant in univariate analysis $(p<0.05)$.

\section{Results}

Atrial fibrillation occurred in 21 of the 90 patients (23.3\%). The time of occurrence of AF clustered around the first three postoperative days with $85.7 \%(18 / 21)$ developing $\mathrm{AF}$ during those days and only $14.2 \%$ (3/21) developing AF between the fourth and the fifth postoperative days. All AF episodes could be reduced with intravenous amiodarone, which is the standard treatment in our institution. No serious sequelae developed because of this arrhythmia, in particular no cerebral embolism. The mean hospital stay was $8.8 \pm 1.7$ days.

\section{Baseline Patient Characteristics}

The preoperative baseline patient characteristics are shown in Table 1 for each group with appropriate univariate $p$-values. Double- or triple-vessel disease was present in $12 / 90$ patients (13.3\%). The right coronary artery and the left circumflex coronary artery were involved in 9 patients each. Postoperative percutaneous dilatation could be performed in 6 patients, and the coronary anatomy of the remaining patients precluded any form of direct myocardial revascularization. Patients in the AF group were significantly older and were more likely to be diabetic. The preoperative use of a $\beta$-blocker, or a calcium channel antagonist, 
Table 2. Operative variables.

\begin{tabular}{llll}
\hline Variable & $\begin{array}{l}\text { SR group } \\
(n=69)\end{array}$ & $\begin{array}{l}\text { AF group } \\
(n=21)\end{array}$ & $p$ value \\
\hline H graft technique & $23.2 C_{C}$ & $33.3 \%$ & 0.53 \\
Lowest systemic temperature $\left({ }^{\circ} \mathrm{C}\right)$ & $33.5 \pm 2.9$ & $33.3 \pm 3.2$ & 0.9 \\
\hline
\end{tabular}

Table 3. Postoperative variables.

\begin{tabular}{llll}
\hline Variable & $\begin{array}{l}\text { SR group } \\
(n=69)\end{array}$ & $\begin{array}{l}\text { AF group } \\
(n=21)\end{array}$ & $p$ value \\
\hline Return to OR & $2.9 \%$ & $4.8 \%$ & 0.55 \\
Myocardial infarction & $1.4 \%$ & $0 \%$ & 0.99 \\
Inotrope support & $2.9 \%$ & $4.8 \%$ & 0.55 \\
Ventilation > 24 hours & $4.3 \%$ & $4.8 \%$ & 0.99 \\
\hline
\end{tabular}

OR: operating room.

or digitalis did not lead to a significant difference between the two groups. The analysis of the type of vessel involved showed that right coronary artery disease was significantly more frequent in the AF group.

\section{Operative Variables}

Because of the absence of cardiopulmonary bypass and myocardial preservation technique, only two operative variables were retained for analysis: neither the technique of grafting, nor the lowest systemic temperature achieved were significantly different in the two groups (Table 2).

\section{Postoperative Variables}

There were no deaths in this group. Four complications directly related to the procedure occurred: one myocardial infarction and three cases of reoperation because of bleeding of the LIMA bed. Notably, all four complications occurred among the initial 20 patients. In part because of the limited number of complications, none differed significantly between both groups (Table 3).

\section{Multivariate Analysis}

Multivariate logistic regression analysis, including the significant variables of the univariate analysis, identified right coronary artery disease as the sole independent correlate for AF. The odds ratio of right coronary artery disease was $6.64(95 \% \mathrm{CI}: 1.34,30.96)$ with a $p$-value of 0.02 .

\section{Discussion}

The incidence of $23.3 \% \mathrm{AF}$ after isolated LIMA-LAD grafting through a minimally invasive approach lies within the range of $20 \%$ to $40 \%$ usually reported for conventional coronary artery bypass grafting [1-5]. In a meta-analysis of 24 controlled randomized trials, Andrews et al. [11] found a pooled proportion of supraventricular arrhythmias (fibrillation or flutter) of $26.7 \%$ with a $95 \%$ CI $(24.7,29.1)$. This variation was attributed to the intensity and duration of postoperative monitoring with an incidence of $41.3 \%$ in the trials that used a period of Holter monitoring vs. $19.9 \%$ for the trials that did not use Holter monitoring. In our study, telemetry monitoring was used for the first 72 hours, and only those arrhythmias that required either medication or pacing were retained for analysis.

Two other works $[8,9]$ have specifically analyzed AF after minimally invasive coronary artery bypass grafting with criteria similar to ours. Cohn et al. [8] reported an incidence of $24 \%$ in 55 patients, and Saatvedt et al. [9] found an incidence of $37 \%$ in a group of 19 patients. These figures, in keeping with our findings, contrast with the lower incidence of $7 \%$ to $13.6 \%$ [12-14] reported in series of minimally invasive coronary artery bypass grafting that did not focus on arrhythmia detection or did not mention the criteria of selection of AF episodes. Moreover, in these studies the mean hospital stay varied between two and three days, and heart rhythm was not closely controlled after patient discharge. Our conservative policy of keeping the patients in hospital for a mean of $8.8 \pm 1.7$ days allowed for better follow-up of such arrhythmias. In the study of Saatvedt et al. [9] the length of stay was not mentioned, whereas the median length of stay in the series of Cohn et al. [8] was 4 days.

Right coronary artery disease was identified as the sole independent predictor of AF. Two previous series of conventional coronary artery surgery patients have suggested the importance of right coronary artery disease in the occurrence of postoperative AF. Mendes et al. [15], in a prospective study of 168 consecutive patients, found right coronary artery disease to be a independent and powerful risk factor: 45 of $105(43 \%)$ patients with proximal or mild right coronary artery stenosis had AF postoperatively compared with 12 of $64(19 \%)$ patients without significant right coronary artery disease. In a series of 200 patients, Pattison et al. [16] reported an incidence of supraventricular arrhythmias of $32 \%$ in patients undergoing right coronary endarterectomy as part of the revascularization procedure but only $19.8 \%$ in patients without right coronary endarterectomy.

The mechanism by which right coronary artery disease may predispose to postoperative AF in these studies remains unclear. Right atrial or ventricular ischemia may play a role, and this is a mechanism more likely to occur in our patient population, which did not have right coronary artery revascularization at the time of the surgical procedure. In the setting of acute myocardial infarction, $\mathrm{AF}$ has been reported in $10.4 \%$ [17]. On the one hand, atrial infarction has been associated with these arrhythmias, and most of these infarctions appeared to be localized to the right atrium and were associated with proximal right coronary artery disease [18, 19]. On the other hand, right ventricular dysfunction has been associated with AF in patients with inferior wall infarction [20]. Therefore, atrial infarction or ischemia, atrial distension, and a raised right atrial pressure have been suggested as potential mechanisms.

Atrial fibrillation has been reported after other thoracic surgical procedures such as lung resection, especially when intrapericardial dissection is necessary [21]. Because in our study the diseased right coronary artery was not revascularized at the time of the coronary grafting procedure, this risk factor for AF may find further application to noncardiac thoracic surgery procedures.

Age, which is commonly reported as the most important risk factor $[1-5]$ in conventional coronary artery surgery, was found significant on univariate analysis, while multivariate analysis showed a borderline $p$-value of 0.6 . This discrepancy may reflect the relationship between the extent of coronary disease, including 
the additional involvement of the right coronary artery, and increasing age.

In conclusion, this prospective study, focusing on AF after minimally invasive coronary artery bypass grafting, found an incidence similar to that reported for conventional surgery. Risk factor analysis discovered right coronary artery disease as the sole independent predictor of AF. This finding may be related to the fact that in this patient population the diseased right coronary artery was not revascularized at the time of the surgical procedure. For the same reason, this risk factor may find a broader application to noncardiac thoracic surgery.

Résumé. La fibrillation auriculaire (FA) est une forme d'arythmie fréquente après pontage coronarien conventionnel. A l'heure du prélèvement mini-invasif de l'artère mammaire interne gauche, nous avons analysé P'incidence et les facteurs de risque de $\mathrm{FA}$ après pontage antérieur gauche. Cette étude prospective a inclus tous les patients ayant eu un by-pass de l'artère antérieure gauche avec prélèvement mini-invasif de l'artère mammaire interne gauche entre jan 1994 et juin 2000. Vingtquatre facteurs de risque possibles de FA ont été rentrés dans une analyse par régression logistique uni- et multivariée. La FA a été constatée chez 21 des 90 patients $(23.3 \%)$ analysés. La maladie intéressait deux ou trois vaisseaux chez $12 / 90$ patients $(13.3 \%)$. En analyse univariée les facteurs de risque étaient la maladie coronaire droite $(p<0.01)$, l'âge $(p=0.01)$ et le diabète $(p=0.04)$. En analyse multivariée, seule la maladie intéressant l'artère coronaire gauche a été retrouvée $(p=0.02)$. Dans cette population de patients, l'incidence de $F A$ après pontage coronarien avec prélèvement mini-invasif est comprise dans la fourchette des valeurs rapportées pour la chirurgie conventionnelle. La maladie coronaire droite est un facteur prédictif indépendant et ceci peut être en rapport avec le fait que dans cette population, l'artère coronaire droite n'a pas été revascularisée au moment de l'acte chirurgical. Pour cette même raison, ce facteur de risque pourrait avoir un rôle plus important en chirurgie thoracique non-cardiaque.

Resumen. La fibrilación auricular (AF) es la arritmia que aparece con más frecuencia tras el "by pass" aorto-coronario convencional. Al incrementarse las técnicas mínimamente invasivas utilizando como injertos la arteria mamaria interna izquierda-la arteria descendente anterior izquierda, hemos analizado la incidencia y los riesgos de AF en esta población de pacientes tratados con dichas técnicas. Este estudio prospectivo comprende a todos aquellos pacientes a los que con técnicas mínimamente invasivas se injertó una vez aislada, la arteria mamaria interna izquierda-arteria descendente anterior izquierda. La casuística incluye a todos los pacientes así intervenidos entre enero de 1994 y junio de 2000. Mediante un análisis de regresión logística uni y multivariante se estudiaron 24 posibles factores de riesgo capaces de originar una fibrilación auricular (AF) postoperatoria. De los 90 pacientes analizados, 21 (23.3\%) desarrollaron una AF postoperatoria. Afectación doble o triple de los vasos se registró en $12 / 90$ pacientes (13.3\%). Los factores de riesgo revelados en un análisis univariante fueron: enfermedad de la arteria coronaria derecha $(p<0.01)$, edad $(p=0.01)$ y diabetes $(p=0.04)$. En el análisis multivariante solo la afectación de la arteria coronaria derecha reveló ser un factor de riesgo significativo $(p=0.02)$. En pacientes intervenidos con técnicas mínimamente invasivas la incidencia de la $\mathbf{A F}$ postoperatoria es similar a la observada en cirugía convencional de "by-pass" aortocoronario. Sólo la afectación de la arteria coronaria derecha constituyó un factor pronóstico independiente. Este hecho podría referirse a que en los pacientes de la población estudiada, la lesión de la coronaria derecha no fue revascularizada durante el tratamiento quirúrgico. Este mismo factor de riesgo puede aplicarse a la cirugía torácica no cardiaca.

\section{References}

1. Leitch JW, Thomson D, Baird DK, et al. The importance of age as a predictor of atrial fibrillation after coronary artery bypass grafting. Thorac. Cardiovasc. Surg. 1990;100:338-342

2. Fuller J, Adams GG, Buxton B. Atrial fibrillation after coronary artery bypass grafting. Is it a disorder of the elderly? J. Thorac. Cardiovasc. Surg. 1989;97:821-825

3. Creswell LL, Schuessler RB, Rosenbloom M, et al. Hazards of postoperative atrial arrhythmias. Ann. Thorac. Surg. 1993;56:539-549

4. Aranki SF, Shaw DP, Adams DH, et al. Predictors of atrial fibrillation after coronary artery surgery: current trends and impact on hospital resources. Circulation 1996;94:390-397

5. Matthew JP, Parks R, Saviano JS, et al. Atrial fibrillation following coronary artery bypass graft surgery: predictors, outcomes and resource utilization. JAMA 1996;276:3000-3006

6. Hashimoto K, Ilstrup DM, Schaff HV. Influence of clinical and he:modynamic variables on risk of supraventricular tachycardia after coronary artery bypass. J. Thorac. Cardiovasc. Surg. 1991;101:56-65

7. Taylor GJ, Malik SA, Colliver JA, et al. Usefulness of atrial fibrillation as a predictor of stroke after isolated coronary artery bypass grafting. Am. J. Cardiol. 1987;60:905-907

8. Cohn WE, Sirois CA, Johnson RG. Atrial fibrillation after minimally invasive coronary artery bypass grafting: a retrospective, matched study. J. Thorac. Cardiovasc. Surg. 1999;117:298-301

9. Saatvedt $\mathrm{K}$, Fiane AE, Sellevold $\mathrm{O}$, et al. Is atrial fibrillation caused by extracorporeal circulation. Ann. Thorac. Surg. 1999;68:931-933

10. Cohn WE, Suen HC, Weintraub RM, et al. The " $H$ " graft: an alternative approach for performing minimally invasive direct coronary artery bypass. J. Thorac. Cardiovasc. Surg. 1998;115:148-151

11. Andrews TC, Reimold SC, Berlin JA, et al. Prevention of supraventricular arrhythmias after coronary artery bypass surgery. Circulation 1991;84:III-236-244

12. Calafiore AM, Vitolla G, Mazzei V, et al. The LAST operation: techniques and results before and after the stabilization era. Ann. Thorac. Surg. 1998;66:998-1001

13. Subramanian VA, McCabe JC, Geller CM. Minimally invasive direct coronary artery bypass grafting: two-year clinical experience. Ann. Thorac. Surg. 1997;64:1648-1655

14. Doty JR, Fonger JD, Salazar JD, et al. Early experience with minimally invasive direct coronary artery bypass grafting with the internal thoracic artery. J. Thorac. Cardiovasc. Surg. 1999;117:873-880

15. Mendes LA, Connelly GP, McKenney PA, et al. Right coronary artery stenosis: an idependent predictor of atrial fibrillation after coronary artery bypass surgery. J. Am. Coll. Cardiol. 1995;25:198-202

16. Pattison CW, Dimitri WR, Williams BT. Dysrhythmias following coronary artery surgery. A comparison between cold cardioplegic and intermittent ischemic arrest $\left(32^{\circ} \mathrm{C}\right)$ with the effect of right coronary endarterectomy. J. Cardiovasc. Surg. 1988;29:601-605

17. Crenshaw BS, Ward SR, Granger CB, et al. Atrial fibrillation in the setting of acute myocardial infarction: the GUSTO-I experience. J. Am. Coll. Cardiol. 1997;30:406-413

18. Lazar E, Goldberger J, Peled H, et al. Atrial fibrillation: diagnosis and management. Am. Heart J. 1998;116:1058-1063

19. Gardin J, Singer D. Atrial infarction: importance, diagnosis and localization. Arch. Intern. Med. 1981;141:1345-1348

20. Rechavia E, Strasberg B, Mager A, et al. The incidence of atrial arrhythmias during inferior wall myocardial infarction with and without right ventricular involvement. Am. Heart J. 1992;124:387-391

21. Krowka MJ, Pairolero PC, Trastek VF, et al. Cardiac dysrhythmia following pneumonectomy. Clinical correlates and prognostic significance. Chest 1987;91:490-495 